\title{
The kick with the kite: an analysis of kite surfing related off shore rescue missions in Cape Town, South Africa
}

\section{A K Exadaktylos, G M Sclabas, I Blake, K Swemmer, G McCormick, P Erasmus}

Br J Sports Med 2005;39:e26 (http://www.bjsportmed.com/cgi/content/full/39/5/e26). doi: 10.1136/bjsm.2004.014795

\begin{abstract}
Background: This study analyses kite surfing related off shore rescue missions in Cape Town, South Africa with the aim of providing more information on the frequency, pattern, and severity of kite surfing related injuries.

Methods: The observation period for this study started on October 1, 2003 and ended on May 1, 2004 and included 30 air rescue missions. Data and information were collected prospectively.

Results: The Air Mercy Service in Cape Town Province responded to 30 requests for help. Twenty five accidents were attributed to inability to detach the kite from the harness. Injuries occurred in five incidents and included fractures of the upper arm, ribs and ankle, and lacerations and contusions to the head and neck. Two patients suffered from hypothermia and one experienced severe exhaustion. All surfers were rescued successfully and there were no fatal accidents.

Discussion: The risk potential of this new sport is unclear. Dangerous situations can occur despite proper training and safety precautions due to unpredictable conditions and difficulties with equipment. Safety should be stressed. Surfers should sailing with a fellow kiter and should wear a life vest. More efforts must be taken to make this booming new water sport safer.
\end{abstract}

$\mathrm{K}$ ite surfing is one of the newest and trendiest disciplines in outdoor sports in South Africa. Kite surfing is like a between wind surfing, wake boarding, an paragliding. Kite surfers control a wing of lightweight fabric, which pulls them across the water or above it (for further information see http://encyclopedia.thefreedictionary.com/ Kite\%20surfing). In 1996 kite surfing had its first worldwide media exposure as a new sport thanks to the wind surfers Laird Hamilton and Manu Bertin. Although the sport of kite surfing is brand new, it is not a new invention and the concept was applied in eastern cultures a long time ago. In fact, in China and Polynesia, kite sailing was a form of transportation in the Pacific Rim beginning in the 13th and 14th centuries! Indonesian and Polynesian kite fishermen dragged their canoes with kites as early as the 12th century (see http://sportsvl.com/water/kitesurfing.htm).

A modern surf kite flies by opposing the force of the wind with the tension of a string held by the operator who is standing on predominantly fibreglass boards. These large kites are designed to provide significant pull and come in two main forms: foils and leading edge inflatables. Most kites now use a similar design with inflatable bladders and struts which assist greatly in re-launching the kite from water. There are several different control systems used with these kites which have three to five lines and a bar or handles. In the neutral position, in which the kite is straight overhead, there is no pulling of the kite except against the surfer's body weight. The surfer then lies down in the shallows and straps the board onto their feet. Then, in a coordinated movement, the kite is flown towards the water in the direction in which the board points. If the board does not dig into the water or a wave, the kite pulls the surfer up in a powerful planeing motion similar to water skiing. Off shore, jumping is very popular, using a power kite to pull the jumper tens of feet above the waves in a controlled leap (for further details see http://encyclopedia.thefreedictionary.com/Kite\%20surfing). Photographs of this dynamic new water sport are shown in figs 1 and 2 .

The popularity of kite surfing has quickly increased over the past 2 years making it one of the fastest growing water activities. Today there are worldwide organisations, competitions, videos, and magazines dedicated to this increasingly popular sport. In South Africa kite surfers already outnumber the wind surfing community.

In order to present the first search and rescue related data of this new off shore sport, we prospectively collected the data of all kite board related rescue missions performed by the Cape Town chapter of the South African Red Cross Air Mercy Service between October 2003 and May 2004. With this study we hope to shed more light on the frequency, pattern, and severity of kite surfing related injuries. Better understanding of the risks of kite surfing might also help manufacturers and instructors develop further measures to prevent serious injuries.

\section{METHODS}

The Air Mercy Service (AMS) in Cape Town Province provides aero-medical and rescue services in partnership with the provincial administration, emergency medical services, and the Wilderness Search and Rescue Organisation (WSAR) and employs an air ambulance helicopter (an MB B0105) and a rescue helicopter (an Alouette III, recently replaced by a AS350 B2; fig 3). AMS is the medical first response rescue organisation for this type of emergency. The observation period for this study started on October 1, 2003 and ended on May 1, 2004 and included 30 missions to rescue kite surfers. Data and information were collected prospectively.

\section{RESULTS}

The AMS undertook about 800 helicopter flights during the study period, of which 121 were rescue missions (table 1). AMS responded to 30 requests for sea rescue. Of these 30 missions, 25 were in support of the National Sea Rescue Institute (NSRI) and five were based on primary rescue calls made by fellow surfers or a beach guard. A total of 25 accidents $(83 \%)$ were attributed to inability to detach the kite from the harness in a situation involving loss of control over the kite due to very strong winds far away from the beach or

Abbreviations: AMS, The Air Mercy Service; NSRI, National Sea Rescue Institute; WSAR, Wilderness Search and Rescue Organisation 

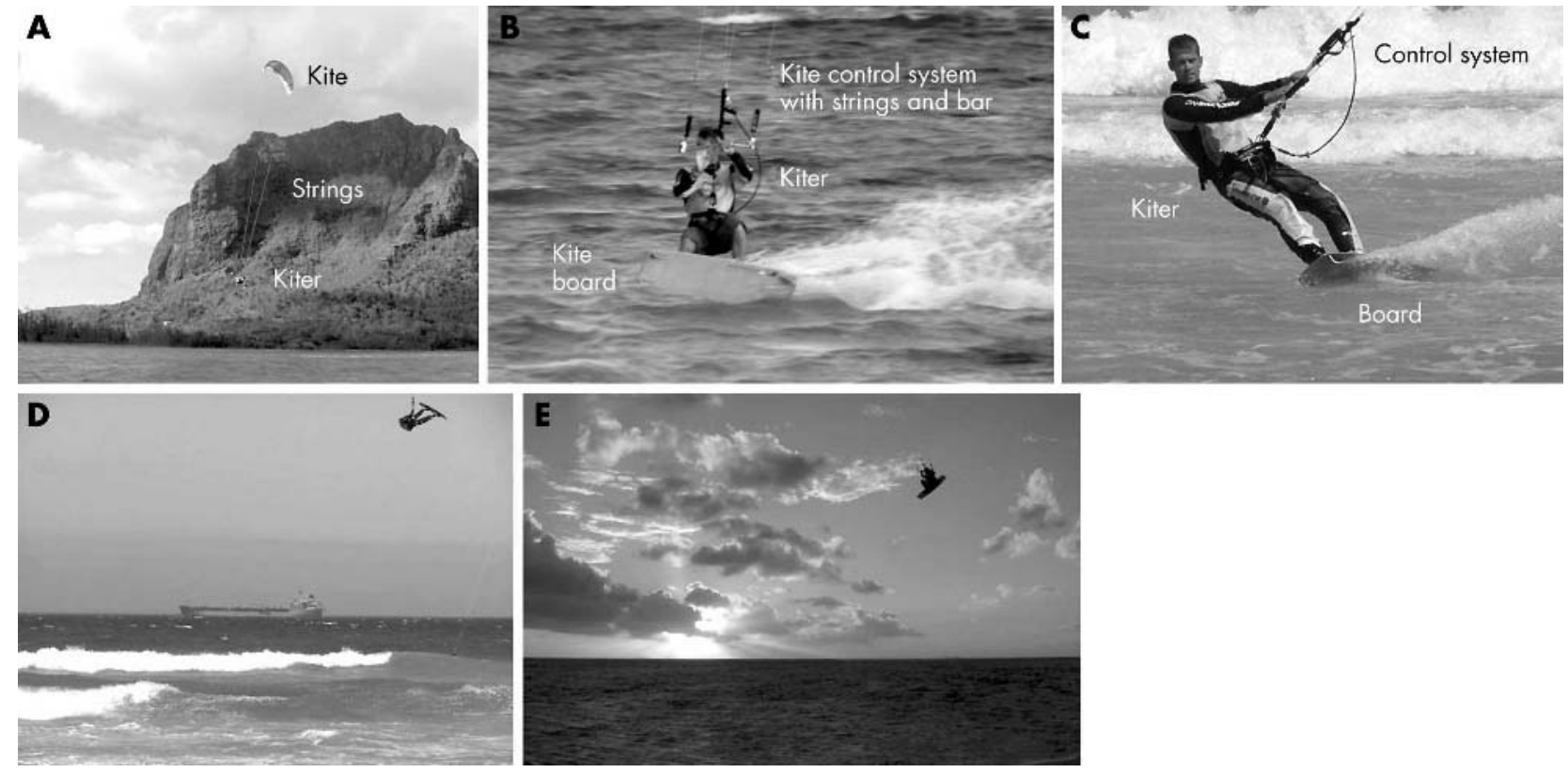

Figure 1 Kite surfer in action. (A) Typical view of a kite surfer as seen from the beach. (B, C) Close up of a kiter displaying the equipment and dynamics of this new sport. (D) A jump over the open sea. (E) Sunset jump. (Photographs are reproduced with permission of Mr Reg Sieberhagen, Cape Town, South Africa.)

inability to launch the kite off shore due to weak winds. These were pure search missions and the kite surfer was not taken on board the helicopter, but brought ashore by an NSRI



Figure 2 A dangerous situation. The surfer is pulled up in the air by his kite due to strong winds and has lost control over the kite. In this situation a timely detachment from the kite is crucial to prevent serious injuries. (Photograph are reproduced with permission of Mr Reg Sieberhagen, Cape Town, South Africa.) boat. Five rescue missions (17\%) were injury related. All 30 rescued persons had got too far away from the coast line and, to our surprise, were not wearing life vests. Mean age was 26 years (range 23-35). There were 27 males and three females involved in the accidents. All 30 surfers were rescued successfully and there were no fatal accidents.

The following injuries were observed. Two patients were hit by their boards and suffered from fractures of the humerus, ribs, and ankle. Both patients underwent surgery for their bone fractures. Two other patients were dragged into the open sea due the kite failing to detach and suffered from hypothermia and exhaustion. Both patients needed admission to a hospital critical care unit for their hypothermia. The fifth injured patient suffered from severe exhaustion and lacerations and contusions in the head and neck region. $\mathrm{He}$ was treated on an outpatient basis. All five injured individuals were male.



Figure 3 Combined rescue mission of WSAR with helicopter support from the AMS. 
Table 1 Air rescue services provided by AMS in Western Cape Province

\begin{tabular}{lrc}
\hline Search and rescue helicopter missions, Alouette III October 1, 2003-May 1, 2004 & No. of calls & Average airborne time per mission \\
\hline Requests (mountain and sea rescue) & 121 & $1.9 \mathrm{~h}$ \\
Primary sea rescue for kite surfers supported by the AMS & 25 & $0.6 \mathrm{~h}$ \\
Primary response to rescue calls for kite surfers & 5 & $0.7 \mathrm{~h}$ \\
\hline
\end{tabular}

\section{What is already known on this topic}

The pattern and frequency of kite surfing injuries are largely unknown although the sport is similar to other water sports activities, such as wind surfing, water skiing, and wakeboarding. According to previous studies, a quick release system enabling the surfer to detach the kite in dangerous situations might aid in the prevention of injuries.

\section{DISCUSSION}

Kite surfing is the natural evolution of extreme wind powered sports such as wind surfing, wake boarding, and paragliding, and in its short history has brought together the most exciting components of these activities. ${ }^{12}$ To date the risk potential of this new sport is unclear. Dangerous situations can occur even with proper training and safety precautions due to unpredictable off shore conditions and difficulties with the equipment. Physicians and rescue crews are likely to see patients with spinal and chest injuries, anterior shoulder dislocation, and back pain sustained during falls when hitting the waves. Further upper and lower extremities are at risk for fractures caused by hitting kite boards. Skin lacerations, sun burn, and cranio-facial traumas will be further injuries associated with kite surfing.

The key to preventing injuries and dangerous situations is to stress off shore and beach safety. Protective head gear helps avoid lacerations, concussions, and other brain injuries. Helmets designed and certified for wind surfing and water skiing are readily available and have a light, impact resistant plastic shell and provide adequate peripheral vision and hearing. ${ }^{3}$ Kite surfers should always wear helmets because of the risk of hitting the waves head first. A personal flotation device is highly recommended and is life saving if the surfer losses control of the kite and is unable to detach the kite from the harness and is dragged into the open sea. Furthermore, a life vest, as well as a wet or dry suit, can prevent hypothermia. As our data show, none of the rescued persons was wearing a life vest. Gloves can decrease the risk of injuries to the hands.

Regarding national sea rescue guidelines, kite surfers should never venture onto the water in off shore winds. The best direction is cross shore as in a strong wind with flat water it is possible to travel at $50 \mathrm{~km} / \mathrm{h}$ (30 miles/h) or more. Beginners should turn by going to the shallows or other stopping area, putting the kite up into neutral, and then turning the kite in the opposite direction to avoid collisions with other surfers or people on the beach. An unskilful turn can cause the surfer to fly, and is often followed by a fall if the surfer is unable to position the board at the correct angle; injuries are common. "Flying" a kite can be a high impact contact sport. Flying occurs when the surfer pulls the kite.

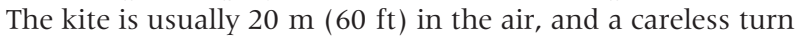
in high winds can easily swing the surfer $5 \mathrm{~m}$ into the air and down to uncontrolled contact with other surfers or even the beach and can cause severe head and neck injuries. This is extremely dangerous and should never be tried near or above

\section{What this study adds}

With this study we hope to shed more light on the frequency, pattern, and severity of injuries sustained when kite surfing, one of the trendiest outdoor sports activities in South Africa. Better understanding of the risk of kite surfing might also help manufacturers and instructors develop further measures to prevent serious injuries.

land. Lightweight people can easily be carried off and smashed against water, buildings, dunes, and power lines.

A kite board, like a wind surfing board, is considered a sailing vessel, and so kite surfers must follow the usual rules of sailing and respect other people in the water. Sailing with a fellow kiter can ensure that help is available in case of an accident or equipment failure. Fatal accidents like the case of a 38 year old who became the first kite surfer to be killed in Britain in August 2003 after a gust of wind swept him $50 \mathrm{ft}$ along Calshot beach, near Southampton, and hurled him head first into a sea wall, are rare but should remind us of the dangers related to this new trendy sport. More effort should be taken in the future to make this new exciting water sport safer.

\section{ACKNOWLEDGEMENTS}

We would like to thank all the men and women, volunteers, staff, and donors, who make the life saving work of the Red Cross Air Mercy Services a reality. We would like to thank Mr Reg Sieberhagen, one of Cape Town's finest kite surfers, for using some of his private surf pictures for this publication.

\section{ELECTRONIC-DATABASE INFORMATION}



Information on kite surfing cam be found at http:// encyclopedia.thefreedictionary.com/Kite\%20surfing and at http://sportsvl.com/water/kitesurfing.htm.

\section{Authors' affiliations \\ A K Exadaktylos, I Blake, K Swemmer, G McCormick, P Erasmus, South African Red Cross Air Mercy Service, Cape Town, South Africa G M Sclabas, UT MD Anderson Cancer Center, Houston, TX, USA \\ Competing interests: none declared. \\ Photographs are reproduced with permission.}

Correspondence to: Dr Aristomenis K Exadaktylos, Department of Anesthesiology and Emergency Medicine, Inselspital, University Hospital Bern, 3010 Bern, Switzerland; aristomenis@exadaktylos.ch

Accepted 21 December 2004

\section{REFERENCES}

1 American Windsurfing Industries. Summary of available research. See www.maui.net/ hotwind/uska.html (accessed 4 March 2005).

2 Rosenbaum DA, Dietz TE. Windsurfing injuries. Phys Sportsmed, 2002;30(5), available at www.physsportsmed.com/issues/2002/05_02/ rosenbaum.htm. 
3 Nickel C, Zernial O, Musahl V, et al. A prospective study of kitesurfing injuries. Am J Sports Med 2004;32(4):921-7.

4 Petersen W, Hansen U, Zernial O, et al. [Mechanisms and prevention of kitesurfing injuries]. Sportverletz Sportschaden 2002;16(3):115-21 (in

German).

\section{COMMENTARY}

he authors describe their experience with injuries related to a new type of sport, kite surfing. In fact, a rapidly rising number of new sports have emerged during the last three decades. Just remember: who knew about paragliding, mountain-biking, etc, 20 years ago? However, with the new sports we have to learn about their specific patterns of injury. As kite surfing is a very new outdoor sport, we cannot as yet really estimate its risk potential. There are only very few data on this topic, so the preliminary data presented by the authors are welcome. All physicians engaged in the treatment of sports-related injuries should be encouraged to report on their experience with new "trendy" sports. This will contribute to better knowledge and to the establishment of adequate safety precautions.

Department of Anaesthesiology, University Hospital, Vienna Muhm manfred.muhm@meduniwien.ac.at

his paper describes the complications of the new sport of kite surfing based on rescue missions in Cape Town. It should stimulate future research aimed at: (i) estimating the incidence of complications and therefore the safety of this sport; (ii) providing better guidelines for the safer use of equipment; and (iii) improving the safety of the sport by improving the manufacture of the equipment used.

M Curatolo

Department of Anesthesiology, Division of Pain Therapy, Inselspital, Bern, Switzerland; Michele.curatolo@insel.ch 